\title{
REG4 acts as a mitogenic, motility and pro-invasive factor for colon cancer cells
}

\author{
LOUISA RAFA ${ }^{1 *}$, ANNE-FRÉDÉRIQUE DESSEIN $^{1,2^{*}}$, LOUISE DEVISME $^{3}$, DAVID BUOB $^{3}$, \\ STÉPHANIE TRUANT ${ }^{1,4}$, NICOLE PORCHET ${ }^{1,2}$, GUILLEMETTE HUET ${ }^{1,2}$, \\ MARIE-PIERRE BUISINE ${ }^{1,2^{*}}$ and THÉCLA LESUFFLEUR ${ }^{5,6^{*}}$ \\ ${ }^{1}$ Inserm, U837, Lille F-59045; Université Lille 2, Faculté de Médecine H Warembourg, Lille F-59000; \\ CHRU de Lille, Lille F-59037; ${ }^{2} \mathrm{CHRU}$ de Lille, Centre de Biologie-Pathologie, Laboratoire de Biochimie \\ et Biologie Moléculaire et plateforme de Génétique des tumeurs, Lille F-59037; ${ }^{3} \mathrm{CHRU}$ de Lille, \\ Centre de Biologie-Pathologie, Service d'Anatomie et Cytologie Pathologiques, Lille F-59037; \\ ${ }^{4}$ CHRU de Lille, Service de Chirurgie Digestive et Transplantation, Lille F-59037; \\ ${ }^{5}$ Inserm, U843, Paris F-75019; Université Paris Diderot, Paris F-75205, France
}

Received May 13, 2009; Accepted July 29, 2009

DOI: 10.3892/ijo_00000544

\begin{abstract}
REG4, the latest member of the regenerating gene family, is overexpressed in inflammatory bowel diseases and gastrointestinal carcinomas. To date, its pathophysiologic role has not been well established. Using HT-29 models, we previously identified REG4 as being overexpressed in colorectal tumor cells displaying a drug-resistance phenotype; some also displayed invasive properties. Thus, we investigated the potential functions of REG4 in biological processes involved in colorectal tumor progression such as cell proliferation, migration and invasion. Colon cancer cells secreting REG4 (HT29-5M21, HT29-5F7 and HT29/REG4-8) or not (HT-29, HT29/CT1 and Caco-2/TC7) were used to analyze the autocrine and paracrine effects of REG4. REG4 was continuously secreted into the culture medium of colon cancer cells. REG4 stimulated cell growth in a paracrine manner after $24 \mathrm{~h}$ of treatment. Notably, REG4 promoted migration and invasion of tumor cells in both an autocrine and paracrine manner, and these effects were significantly decreased by concomitant treatment with an anti-REG4 antibody. Using
\end{abstract}

Correspondence to: Dr Thécla Lesuffleur, ${ }^{6}$ Present address: Inserm, UMR S 938, Centre de Recherche Saint-Antoine, 184 rue du Faubourg Saint-Antoine, Paris F-75012, France

E-mail: thecla.lesuffleur@inserm.fr

*Contributed equally

Abbreviations: CRC, colorectal carcinoma; CM, conditioned medium; IBD, inflammatory bowel diseases; REG1A, regenerating islet-derived $1 \alpha$; REG3A, regenerating islet-derived $3 \alpha$; REG4, regenerating islet-derived 4; UACL, ulceration-associated cell lineage

Key words: colorectal carcinomas, regenerating islet-derived 4 proliferation, migration and invasion, fetal intestine pharmacological inhibitors, we showed that PI3K/Akt, PKAs, PKCs and Rho-like GTPases, but not MAPK, are involved in REG4 invasion signals. In addition, REG4 expression was found to be increased in tissues harboring proliferation and migration properties such as the developing intestine and tissues from inflammatory bowel disease, hyperplastic polyps, adenoma and colorectal cancers. In various situations, REG4 expression was not confined to proliferating cells, regenerating cells or cells of the invasive front of metastatic tumors, suggesting that extracellular REG4 may act on epithelial cells in a paracrine manner. Altogether, our results indicate that REG4 is a multifunctional secreted protein which acts on colorectal cancer cells in an autocrine and paracrine manner. According to its biological functions and tissue expression, REG4 may play an important role in the development and progression of colorectal cancer, as well as in intestinal morphogenesis and epithelium restitution.

\section{Introduction}

The REG (regenerating) genes form a family belonging to the calcium-dependent lectin (C-type lectin) gene superfamily. REG proteins are small secreted proteins $(16.5 \mathrm{kDa})$ that contain a single well-conserved carbohydrate-recognition domain (1). In humans, four members have been identified to date and have been grouped into three subclasses based on the primary structure of the encoded proteins: REG1A and REG1B (type I subclass), REG3A (type III subclass) and REG4 (type IV subclass). As reported in numerous publications, increased expression of REG proteins in various tissues is often related to injury, inflammation or carcinogenesis supporting the multifunctionality of these proteins $(1,2)$. REG4, the most recent member of the $R E G$ gene family to be characterized, was first identified as being up-regulated in ulcerative colitis which suggests that REG4 protein may play a role in inflammatory bowel diseases (3-5). It has been shown that REG4 is also overexpressed in cancers of the 
stomach, colon, pancreas and prostate (6-10). The overexpression of REG4 in colorectal and gastric carcinomas has been reported at both the mRNA and peptide levels, and is associated with goblet and neuroendocrine cell differentiation $(6,7,11)$. In colorectal carcinomas, REG4 expression is associated with both tumor stage and metastasis, suggesting involvement of REG4 in tumor progression $(7,11)$. Nevertheless, little information is available on the biological role of REG4 in the pathophysiology of inflammatory bowel diseases and colorectal carcinomas. Like REG1A and REG3A proteins, REG4 may function as a mitogenic and antiapoptotic factor in colon and gastric cancer cell lines $(10,12)$. Bishnupuri et al recently showed that REG4 activates the EGF receptor/Akt/AP-1 signaling pathway in colon cancer cells and increases the expression of anti-apoptotic genes (Bcl-2, Bcl-XL and survivin) (12).

In a previous study using differential display-PCR in HT-29 models, we identified REG4 as a gene that might be involved in the survival pathways developed by drugresistant cells (6). REG4 was highly overexpressed in HT295F7 and HT29-5M21 clones selected from the colon cancer cell line HT-29 by long-term treatment with 5-fluorouracil (13) or methotrexate (14). In contrast to HT-29 cells which are drug-sensitive and undifferentiated $(15,16)$, the drugresistant HT29-5F7 and HT29-5M21 clones exhibited differentiation features associated with either an enterocytelike phenotype or a mucus-secreting phenotype, respectively $(13,14)$. Notably, the mucus-secreting HT29-5M21 clone, selected by resistance to methotrexate, displayed a spontaneous invasive phenotype in a type I collagen layer, whereas parental HT-29 cells are noninvasive under the same conditions (17). Recently, we demonstrated that conditioned medium from HT29-5M21 cells, but not from parental HT-29 cells, induced various colon epithelial cells to invade a collagen layer, supporting a potential role of secreted factor(s) in this spontaneous invasive behavior (18).

Using several cellular models, we demonstrated here that REG4 activates not only cell proliferation but also in vitro migration and invasion of colorectal cancer cells. Accordingly, we identified the signaling pathways involved in REG4activated cell invasion. To complement this in vitro data, we also documented the expression of REG4 in various human intestinal tissues displaying cell proliferation and cell migration properties during intestinal development, healing or carcinogenesis.

\section{Materials and methods}

Cell lines and cell culture. The following human colorectal carcinoma cell lines and subpopulations were used: LS513, LS174T, LoVo, HT-29, the mucus-secreting clone HT295M21 (14) and the enterocyte-like HT29-Glc (19), HT29-5F7 (13) and Caco-2/TC7 [provided by Monique Rousset (20)]. HT-29 cells were stably transfected with the pEF1/V5-His vector (Invitrogen, Cergy Pontoise, France) encoding human REG4 (6), using the Effecten Transfection Reagent (Qiagen, Courtaboeuf, France) according to the manufacturers' instructions. The pEF1/V5-His parental vector was used as a negative control. Stable transfectants were selected after 3 weeks of growth with G418 $(600 \mu \mathrm{g} / \mathrm{ml})$ and subcloned in 24-well plates. The clone secreting the highest amount of REG4-V5-His (HT29/REG4-8) was selected along with a control clone (HT29/CT1) for further experiments. All cell lines were maintained as previously described $(6,13,14)$; culture conditions for HT29/REG4-8 and HT29/CT1 clones being the same as for HT-29 cells. The medium was changed daily in all experiments.

Cell proliferation assay. Cells were seeded on a 24-well plate at a density of $4 \times 10^{4}$ cells/well for HT-29 and $1.6 \times 10^{4}$ cells/ well for Caco-2/TC7. After $24 \mathrm{~h}$, cells were stimulated with various concentrations (0.1-100 $\mathrm{nM}$ ) of recombinant human REG4 (rREG4; BioVendor, Heidelberg, Germany) for 3 days. The addition of exogenous rREG4 was performed daily when the medium was changed. Cell counts, in triplicate, were performed 24,48 and $72 \mathrm{~h}$ after treatment.

Conditioned media and REG4 secretion. REG4 secretion was assessed in relation to cell growth or when the cells reached confluency. At selected growth points, fresh serum-free medium was added and then collected after 24 h. REG4 protein released into this conditioned medium (CM) was analyzed by Western blotting. For each cell line and clone, an equal volume of concentrated CM (filtration on NMWL 3.000 Amicon; Millipore, Saint-Quentin-en-Yvelines, France) was loaded on a $15 \%$ SDS-PAGE gel and analyzed by Western blot analysis using a mouse anti-REG4 antibody (R\&D Systems, Lille, France) or anti-V5 antibody (Invitrogen).

In vitro wound and cellular invasion assays. Wound assays were performed as previously described $(21,22)$. Briefly, confluent monolayers of cells grown in 6-well plates were incubated overnight in serum-free medium and then wounded using a blue pipette tip. Wounded monolayers were washed twice with PBS before incubation in fresh low serum (0.5\%) DMEM, with or without rREG4 $(1,10$ or $100 \mathrm{nM})$ for $0,3,6$ or $9 \mathrm{~h}$. These time points were chosen to prevent any cell proliferation effect. At each time point, photomicrographs at x100 magnification were taken at 2 positions per wound and for three separate wounds for each condition. Migration was assessed by measuring the distance (in $\mu \mathrm{m}$ ) that cells had traveled across the wound using NIS element 2.3 software. Two separate measurements were performed for each photomicrograph.

Collagen type I invasion assays were performed as described previously $(17,23)$. Briefly, rat tail type I collagen (BD System, le Pont-de-Claix, France) in buffered solution was poured into 6 -well plates $(1.25 \mathrm{ml} /$ well $)$ and incubated for $1 \mathrm{~h}$ at $37^{\circ} \mathrm{C}$ to allow gelation. Cells $\left(10^{5}\right.$ cells/well $)$ were then seeded on top of the collagen gel with or without rREG4 $(100 \mathrm{nM})$ and various pharmacological inhibitors: wortmannin (500 nM), KT5720 (500 nM), Gö6976 (1 $\mu \mathrm{M})$, C3T exoenzyme $(5 \mu \mathrm{g} / \mathrm{ml})$, Y27632 $(10 \mu \mathrm{M})$, SB203580 $(10 \mu \mathrm{M})$ and PD098059 $(25 \mu \mathrm{M})$ (Calbiochem Merck Eurolab, Fontenaysous-Bois, France). After a 24 -h incubation period, the number of cells that had invaded the gel was assessed by microscopy, and the invasion index was calculated for each well as the number of cells having invaded the gel over the total number of cells. Invasive and superficial cells adhering 
to the collagen gels were counted in 12 fields of $0.157 \mathrm{~mm}^{2}$ using an inverted microscope, representing a total of 250-300 cells examined and screened for each experimental condition. The invasion index was expressed as the percentage of invading cells versus the total number of cells.

Tissue specimens and immunohistochemistry. Formalin-fixed paraffin-embedded archival tissue samples were obtained from the Department of Pathology of Lille University Hospital. They included tissues from 11 human embryos and fetuses ranging in age from 8 to 30 weeks of gestation (data based on the last menstruation). Pathological tissues comprised specimens from patients with ileal or colonic Crohn's disease $(n=7)$, ulcerative colitis $(n=3)$, hyperplastic polyps $(n=5)$, adenomatous polyps $(n=9$, including 4 with low grade dysplasia and 5 with high grade dysplasia) and carcinomas $(n=17)$. Colorectal carcinomas (CRC) consisted of neuroendocrine $(n=2)$, mucinous $(n=4)$, signet-ring cell $(n=1)$ adenocarcinomas and moderately $(n=6)$ and poorly $(n=4)$ differentiated conventional adenocarcinomas. Corresponding liver metastases were also obtained from 6 patients. Specimens of normal adult intestine [small intestine $(n=6)$, colon $(n=3)$ ] were used as controls.

Immunohistochemical staining procedures for REG4 protein and, when necessary, for Ki67 (a marker of proliferative cells), chromogranin A (a marker of neuroendocrine cells) and MUC2 (a marker of goblet cells) were conducted using an automated Nexes immunostainer (Ventana Medical Systems, Strasbourg, France) and a three-step indirect process based on the biotin-streptavidin-peroxidase method as previously described (24). Tissue sections were incubated with monoclonal mouse antibodies for REG4 (R\&D Systems; 1/100 dilution) and Ki67 (clone MIB-1; Dako, Trappes, France; 1/150 dilution), and polyclonal rabbit antibodies for chromogranin A (Dako; $1 / 200$ dilution) and MUC2 [LUM2-3 from I. Carlstedt (25); 1/1000 dilution], and counterstained with hematoxylin.

Statistical analysis. Single comparisons of data were performed by the unpaired Student's t-test using GraphPad Prism 4.00 (GraphPad Software, USA). p-values $<0.05$ were considered statistically significant.

\section{Results}

Expression of REG4 in colon cancer cells. In a previous study, we identified human colorectal cell lines which expressed REG4 mRNA at various levels (6). Here, we demonstrated by Western blot analysis (Fig. 1A) that among the cell lines in which the highest mRNA levels were previously observed, two cellular clones, HT29-5M21 and HT29-5F7, were also found to secrete the highest amounts of REG4 protein into their culture media. LoVo and LS513 cells secreted intermediate amounts of REG4, whereas a weak protein signal was detected in the culture medium of LS174T and HT29-Glc cells. As expected, no protein was detected in the culture medium of HT-29 and Caco-2/TC7 cells (Fig. 1A). Furthermore, we observed that REG4 was secreted continuously by both dividing and non-dividing cells, as shown for HT29-5F7 cells (Fig. 1B). The amount of REG4
A

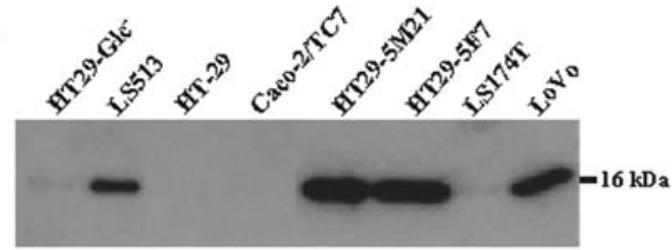

B

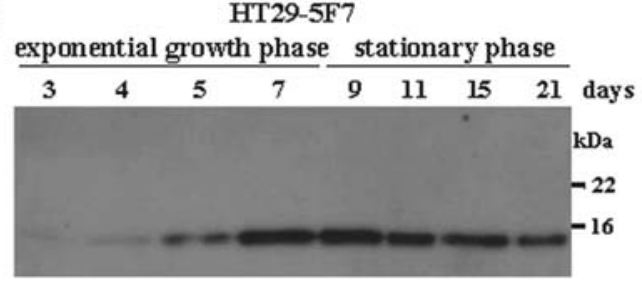

C

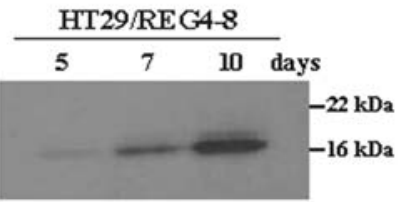

Figure 1. Western blot analysis of REG4 secretion in the culture medium conditioned for $24 \mathrm{~h}$ by tumor cells. (A) Confluent cultures of human colon cancer cells: LS174T, LoVo, LS513, Caco-2/TC7, HT-29, HT29-Glc-, HT29-5F7 and HT29-5M21. (B) During the growth phases of HT29-5F7. (C) HT29/REG4-8 clone stably transfected with the pEF1-hREG4-V5His at days 5, 7 (cell confluency) and 10. All data are representative of 2 independent experiments.

increased during the exponential growth phase (day 3 to 7) up to cell confluency (day 7) and remained high in the medium of late post-confluent cultures (up to day 21). REG4 secretion was also related to growth phases in the HT29/ REG4-8 clone which constitutively expresses human REG4, the highest amount of REG4 protein being observed in postconfluent cells (day 10) (Fig. 1C).

In order to explore the biological functions of REG4 in epithelial cells, some of these models were selected to analyze the autocrine or paracrine effects of REG4 protein on cell proliferation and cell motility, two processes tightly associated with carcinogenesis and tumor progression.

Growth stimulation by exogenous REG4. We first investigated the autocrine effect of REG4 on cell proliferation using REG4 transfectants. There was no significant difference in the growth pattern of REG4-overexpressing cells (HT29/ REG4-8) compared to the control clone (HT29/CT1) (data not shown). We next tested the paracrine effect of REG4 on the growth of HT-29 and Caco-2/TC7 cells that do not secrete endogenous REG4. Cells were treated with increasing concentrations of rREG4 (0.1-100 nM) for $72 \mathrm{~h}$. rREG4 was added daily to the culture medium to mimic continuous REG4 secretion by cells (Fig. 1B). After $24 \mathrm{~h}$ of treatment, REG4 significantly stimulated the proliferation of both HT-29 and Caco-2/TC7 cells as shown in Fig. 2. No significant dose-dependent effect of REG4 on cell growth was observed (Fig. 2A and B). After 48 and $72 \mathrm{~h}$ of treatment, the effect of REG4 on cell proliferation was maintained, but no further increase in cell number was observed after repeated 
A

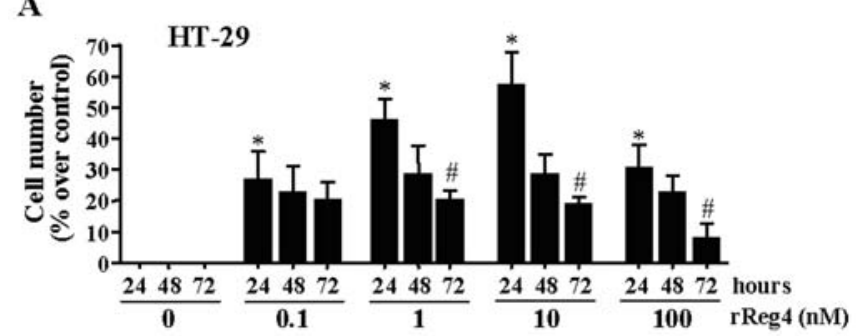

B

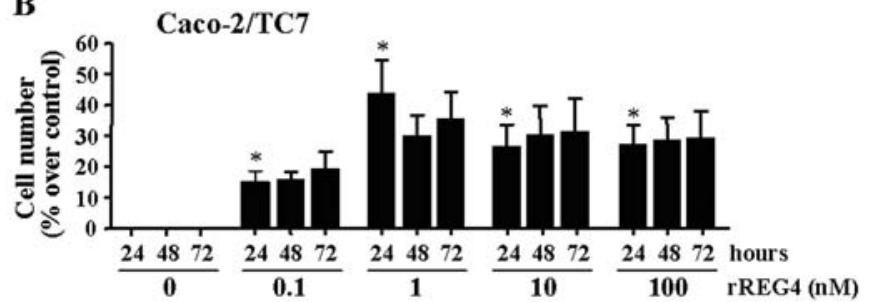

Figure 2. Exogenous REG4 stimulates growth of HT-29 and Caco-2/TC7 cells. Human rREG4 was added daily to the culture medium (0.1-100 nM), and the number of cells was evaluated by cell counts every $24 \mathrm{~h}$. Stimulation of the growth of HT-29 (A) and Caco-2/TC7 (B) cells was observed from the first day of treatment with rREG4, without a significant dose-dependent effect. This effect was less at $72 \mathrm{~h}$ in HT-29 cells. The results represent the mean \pm SEM from 3 independent experiments. ${ }^{*} \mathrm{p}<0.05$ for each concentration tested and for both cell lines when compared to untreated cells; ${ }^{\#} \mathrm{p}<0.05$ significantly different from cells treated for $24 \mathrm{~h}$.

stimulation by rREG4 (Fig. 2A and B). This effect on cell proliferation was even less in HT-29 cells after daily addition of REG4 to the culture medium (at 72 h) (Fig. 2A).

Involvement of REG4 in wound healing and invasion. In a previous study, we described the spontaneous invasive phenotype of HT29-5M21 cells (17). As recently reported, this phenotype may be conveyed by secreted factors (18). Since REG4 is secreted by HT29-5M21 cells, we tested the possibility that REG4 might play a role in migration and invasion processes. Firstly, we assessed the motility of tumor cells using an in vitro cell wound model. As shown in Fig. 3A, the REG4-secreting clones, HT29-5M21 and HT29-5F7, migrated more rapidly than the HT-29 cells that do not express REG4. The capacity of REG4 to promote cell migration was evaluated by incubating the cells with an anti-REG4 antibody $(15 \mu \mathrm{g} / \mathrm{ml})$. Under these conditions, the migration potential of HT29-5M21 and HT29-5F7 cells was significantly decreased (Fig. 3A), suggesting that secreted REG4 protein is involved in this enhanced cell migration. The effect of REG4 on cell migration was then confirmed using cells that do not express REG4, HT-29 and Caco-2/TC7 cells, treated with rREG4. Confluent cell monolayers were wounded and subsequently incubated with increasing concentrations of rREG4 (1$100 \mathrm{nM})$. rREG4 was found to significantly stimulate the migration of both cell lines (Fig. 3B and C). Enhanced wound covering was detected from $3 \mathrm{~h}$ after exposure to REG4 and therefore before any cell division occurred. This effect was blocked by pre-treatment of cells with an anti-REG4 antibody (Fig. 3B and C).

We further examined the potential role of REG4 in the invasive properties of colon tumor cells using a collagen type I invasion assay. As shown in Fig. 4A, LoVo, HT29-5M21 and
A

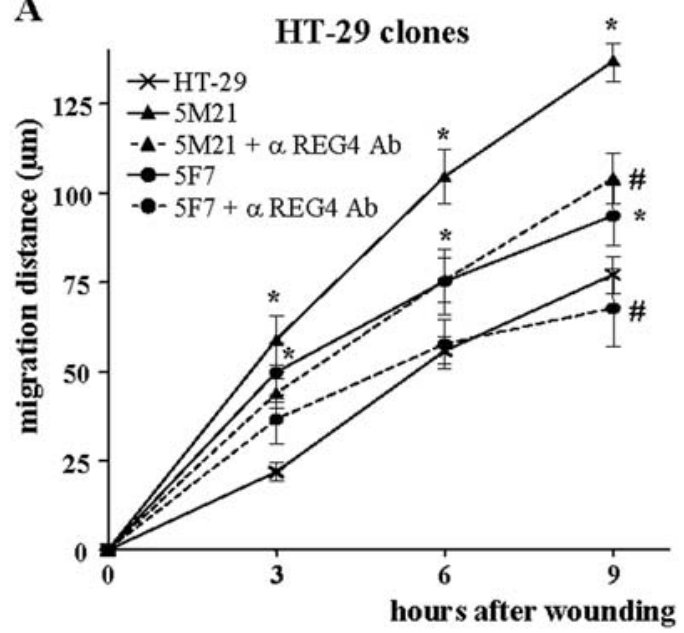

B

HT-29

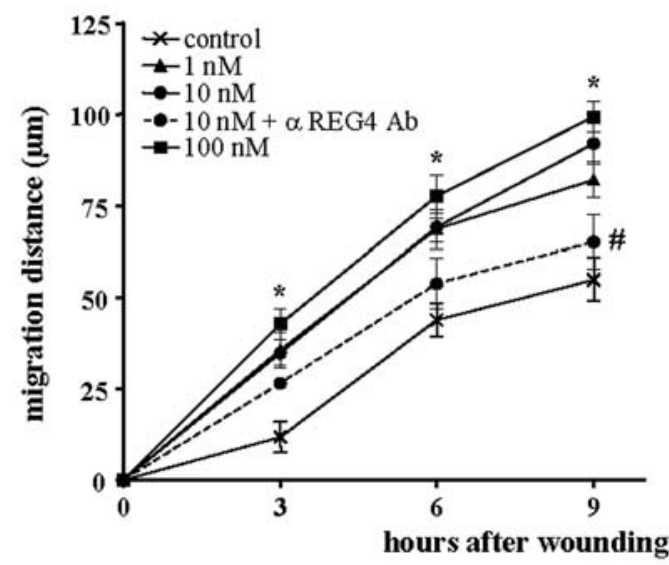

C

Caco-2/TC7

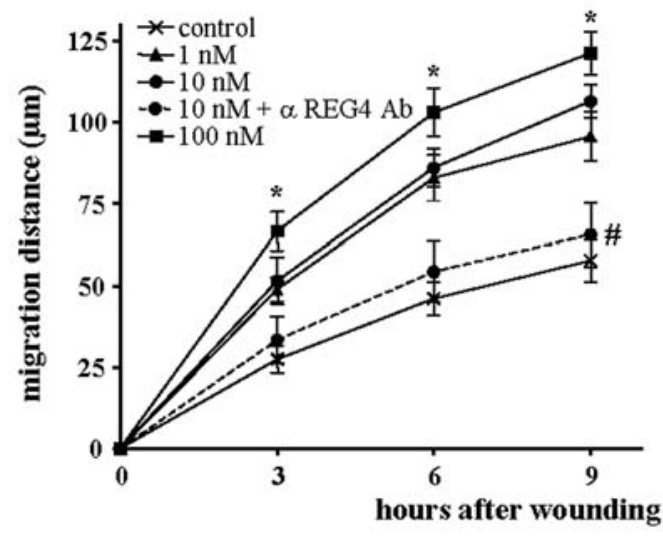

Figure 3. REG4 enhances migration of colon cancer cells. Wounding assays were used to analyze the autocrine (A) and paracrine (B and C) influence of REG4 on the migration of HT29-5F7, HT29-5M21, HT-29 and Caco-2/TC7 cells. Migration was assessed 3, 6 and $9 \mathrm{~h}$ after wounding by measuring the distance (in $\mu \mathrm{m}$ ) covered by migrating cells from the edge of the wound. The results represent the mean distance \pm SEM for 3 different wounds in each specified culture condition. (A) REG4-secreting cells, HT29-5F7 and HT29-5M21, migrated more efficiently than HT-29 cells which do not express REG4 ( ${ }^{*} \mathrm{p}<0.05$ between each clone and HT-29 cells). Treatment with an anti-REG4 antibody $(15 \mu \mathrm{g} / \mathrm{ml})$ resulted in reduced migration of HT-29 clones ( $\left.{ }^{\#} \mathrm{p}<0.05\right)$. (B and C) rREG4 (1-100 nM) induced significantly increased migration of HT-29 and Caco-2/TC7 cells ( ${ }^{*} \mathrm{p}<0.05$ for each concentration tested at 3,6 and $9 \mathrm{~h}$ after wounding and for both cell lines when compared to control cells). Treatment with an anti-REG4 antibody blocked migration of cells induced by $10 \mathrm{nM}$ of rREG4 $\left({ }^{\#} \mathrm{p}<0.05\right)$. All data are representative of at least 2 independent experiments. 
A

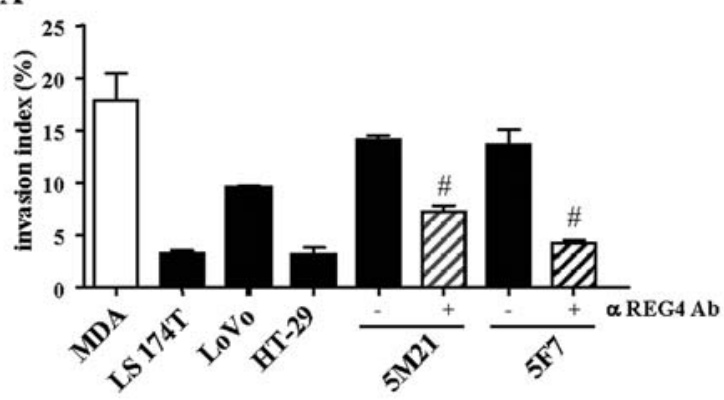

B

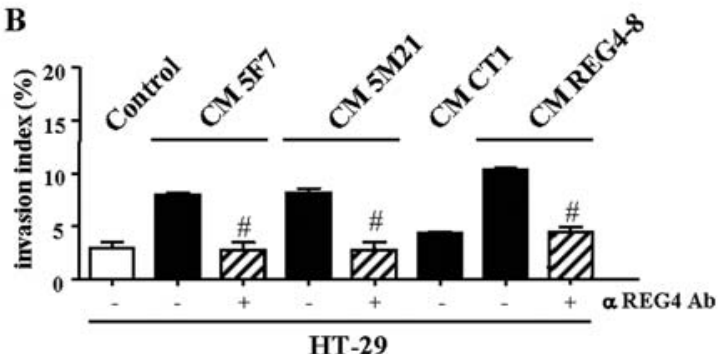

C

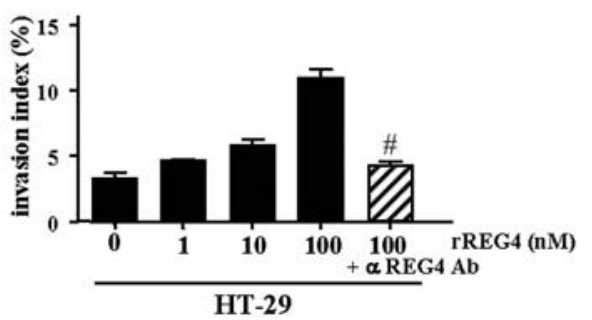

Figure 4. REG4 induces cell invasion. (A) Collagen type I invasion assays with colon cancer cells secreting REG4 protein (HT29-5M21, HT29-5F7, LoVo and LS174T) or not (HT-29) compared to invasive MDA cells used as positive control. The invasive potential of HT29-5M21 and HT29-5F7 cells was significantly reduced in the presence of the anti-REG4 antibody $(15 \mu \mathrm{g} /$ $\mathrm{ml}$ ) (hatched bars) ( $\left.{ }^{\#} \mathrm{p}<0.05\right)$. (B) Paracrine effect of REG4 on HT-29 cell collagen type I invasion. Invasion assays were performed with HT-29 cells in control conditions (open bar) or in the presence of CM from HT29-5M21, HT29-5F7, HT29/CT1 or HT29/REG4-8 cells, either alone (filled bars) or combined with the anti-REG4 antibody (hatched bars) $\left({ }^{*} \mathrm{p}<0.05\right)$. (C) Dose effect of rREG4 (0-100 nM) on collagen type I invasion by HT-29 cells. This effect was reversed in the presence of the anti-REG4 antibody $(15 \mu \mathrm{g} /$ $\mathrm{ml}$ ) (hatched bar) $\left({ }^{\#} \mathrm{p}<0.05\right)$. All the results are expressed as the percentage of invasive cells in the collagen layer. Data are mean \pm SEM from 3 independent experiments.

HT29-5F7 cells were spontaneously invasive, whereas HT-29 and LS174T cells were non-invasive compared with invasive MDA cells. Interestingly, the former express and secrete REG4 whereas the latter secrete no or only weak amounts of REG4 (Fig. 1A). Addition of an anti-REG4 antibody to assays with the invasive cell lines HT29-5M21 and HT295F7 significantly limited their invasive properties (Fig. 4A). These results suggest that the spontaneous invasive phenotype of certain colon cancer cells might be due to secreted factors including REG4 protein. Moreover, as previously described for HT29-5M21-conditioned medium (CM) (18), CM from HT29-5F7 cells also induced invasion of HT-29 cells (Fig. 4B). Pre-incubation of CM with an anti-REG4 antibody abolished the pro-invasive properties (Fig. 4B). Similar results were obtained with CM from HT29/REG4-8

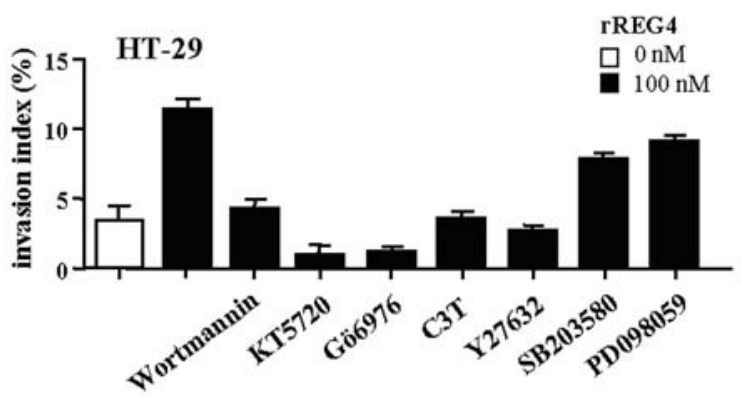

Figure 5. Involvement of several pro-invasive pathways in REG4-induced colon cancer cell invasion. Collagen type I invasion assays were performed using HT-29 cells in control conditions (open bar) and in the presence of rREG4 (100 nM) (filled bar), alone or combined with pharmacological inhibitors targeting PI3-kinase (wortmannin), PKAs (KT5720), PKCs (Gö6976), Rho-GTPases (C3T exoenzyme), ROCK (Y27632), p38 (SB203580) and p42/p44 (PD098059) MAPKs. Data are the mean \pm SEM from 2 experiments.

cells, but not with CM from control HT29-CT1 cells (Fig. 4B). Finally, using rREG4 protein, we confirmed that REG4 acts as a pro-invasive factor for HT-29 cells (Fig. 4C). Preincubation of rREG4 $(100 \mathrm{nM})$ with its antibody blocked the effect of REG4 on in vitro invasion of HT-29 cells (Fig. 4C).

Activation of REG4 downstream pathways. To determine which downstream pathways are involved in the cell invasion processes induced by REG4, we tested the invasive properties of HT-29 cells in the presence of rREG4 $(100 \mathrm{nM})$ alone or combined with pharmacological inhibitors targeting the main pathways activated in cell invasion models. As shown in Fig. 5, the PI3-kinase inhibitor, wortmannin, reduced REG4induced invasion of HT-29 cells. The pro-invasive action of REG4 was equally abolished by other pharmacological inhibitors targeting signaling molecules such as cAMP/PKA (KT5720) and PKC (Gö6976). Use of the C3T exoenzyme and Y27632 pharmacological inhibitors also showed that the Rho-GTPase and the Rho-kinase pathway was activated during REG4-induced invasion of HT-29 cells. In contrast, the pro-invasive action of REG4 was not affected by pharmacological inhibitors of the mitogen-activated protein kinases (MAPKs) p38 (SB203580) and p42/p44 (PD098059).

REG4 expression in developing and pathological intestinal tissues. Our in vitro results support a role for REG4 in both the proliferation and migration of intestinal cells, in a paracrine and/or autocrine manner. In order to provide in vivo evidence, we analyzed the expression of REG4 in human intestinal tissues representative of developmental and pathological situations in which cell proliferation and migration processes are particularly active.

Expression of REG4 was analyzed in 11 embryos and fetuses ranging in age from 8 to 30 weeks of gestation (Table I). REG4 protein was first detected at 10.5 weeks in the fetal small intestine in rare endocrine cells of primitive crypts (data not shown). At 12 weeks, REG4 was present in numerous enteroendocrine cells of primitive crypts and villi, as well as in rare goblet cells (Fig. 6A). From 16 weeks, the pattern of REG4 expression in the small intestine was similar 
Table I. REG4 expression in embryonic, fetal and adult intestine.

\begin{tabular}{|c|c|c|c|c|c|c|c|}
\hline \multirow[b]{2}{*}{ Tissue } & \multicolumn{7}{|c|}{ Age } \\
\hline & $\begin{array}{l}8-9 \text { weeks } \\
\quad(n=2)\end{array}$ & $\begin{array}{c}\text { 10-11 weeks } \\
(n=2)\end{array}$ & $\begin{array}{c}12 \text { weeks } \\
(\mathrm{n}=1)\end{array}$ & $\begin{array}{c}16 \text { weeks } \\
(n=1)\end{array}$ & $\begin{array}{c}18 \text { weeks } \\
(n=1)\end{array}$ & $\begin{array}{c}24-30 \text { weeks } \\
\quad(n=4)\end{array}$ & $\begin{array}{l}\text { Adult } \\
(\mathrm{n}=9)\end{array}$ \\
\hline \multicolumn{8}{|l|}{ Small intestine } \\
\hline Enteroendocrine cells & - & + & +++ & +++ & +++ & $+++/++++$ & $+++/++++$ \\
\hline Goblet cells & NA & NA & $+\mathrm{R}$ & + & + & $+/++$ & $+/++^{\mathrm{a}}$ \\
\hline \multicolumn{8}{|l|}{ Colon } \\
\hline Enteroendocrine cells & NA & NA & NA & ++ & +++ & +++ & +++ \\
\hline Goblet cells & NA & NA & NA & $+\mathrm{R}$ & + & $+/++$ & $+\mathrm{R}$ \\
\hline
\end{tabular}

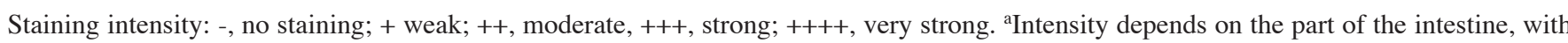
more intense staining in the ileum compared to the duodenum and jejunum. NA, not adapted (undifferentiated cells); R, rare cells.

Table II. REG4 expression in pathological intestinal tissues.

\begin{tabular}{lcc}
\hline Tissues & REG4 staining \\
\hline Inflammatory bowel diseases (n=10) & & \\
Ileal Crohn's disease & $++/+++$ & $(5 / 5)$ \\
UACL & - & $(3 / 3)$ \\
Colonic Crohn's disease & $++/+++$ & $(2 / 2)$ \\
Ulcerative colitis & $+/++++^{\mathrm{a}}$ & $(3 / 3)$ \\
Colonic polyps (n=14) & & \\
Hyperplastic polyps & +++ & $(5 / 5)$ \\
Adenomatous polyps & & \\
With low grade dysplasia & $++/+++$ & $(4 / 4)$ \\
With high grade dysplasia & $++/+++$ & $(4 / 5)$ \\
& $-/++++^{\mathrm{a}}$ & $(1 / 5)$ \\
Colonic carcinomas (n=17) & & \\
Neuroendocrine & & \\
Well-differentiated & & $(1 / 1)$ \\
Poorly differentiated & +++ & $(1 / 1)$ \\
Mucinous & - & $(4 / 4)$ \\
Signet ring cell & +++++ & $(2 / 6)$ \\
Traditional adenocarcinomas & +++ & $(1 / 1)$ \\
Moderately differentiated & & \\
Poorly differentiated & + & $(6 / 6)$ \\
& - & $(1 / 4)$ \\
Liver metastases (n=6) & + & $(3 / 4)$ \\
& - & $(4 / 6)$ \\
\hline
\end{tabular}

Staining intensity: -, no staining; + , weak; ++ , moderate, +++ , strong; ++++ , very strong. ${ }^{a}$ Heterogeneous staining. UACL, ulceration-associated cell lineage.

to that observed in normal adult ileum with protein REG4 in most enteroendocrine cells and goblet cells (Fig. 6B and C); a maximum of staining intensity was reached by 24 weeks (Table I). In the fetal colon, REG4 was observed from 16 weeks in both enteroendocrine and goblet cells (Table I and Fig. 6D), with a maximum for REG4 staining at 24 weeks (Fig. 6E). In contrast, when most enteroendocrine cells expressed REG4 in the normal adult colon, only rare goblet cells stained faintly (Fig. 6F).

In order to gather data on the potential role of REG4 in mucosal healing, the pattern of REG4 expression was analyzed in intestines from patients with inflammatory bowel disease (IBD) (Table II). The lesions consisted mainly of ulcers with adjacent mucosa showing features of inflammation with moderate epithelial damage and structural changes. Strong REG4 staining was observed in epithelial cells of the ileum and colon from patients with Crohn's disease (Fig. 7A), as well as in colon specimens from patients with ulcerative colitis (data not shown). Nevertheless, REG4 was not detected in cells from the ulceration-associated cell lineage (UACL) observed in ileal mucosa from 3 patients with Crohn's disease (Fig. 7A).

REG4 expression was further studied in hyperplastic polyps, common benign lesions of the colorectum, as well as in adenomatous polyps, and carcinomas (Table II). REG4 expression was observed in all hyperplastic polyp specimens analyzed (5/5). Staining was present in enteroendocrine cells and goblet cells all along the epithelium of villi and crypts (Fig. 7B), whereas only cells confined to the lower half of the crypts were positive for Ki67. REG4 was also detected in all adenomatous polyp specimens tested (9/9), regardless of the grade of dysplasia (Table II and Fig. 7C). Staining was strong and present all along the epithelium, similarly to Ki67. Among CRC specimens, REG4 was present in one welldifferentiated neuroendocrine carcinoma positive for chromogranin A, but not in a second specimen that was poorly differentiated with loss of chromogranin A expression (Table II). REG4 was also detected in all specimens of mucinous carcinomas (4/4) and in a specimen of signet-ring cell carcinoma (1/1) (Table II and Fig. 7D). In poorly and moderately differentiated conventional adenocarcinomas, REG4 was detected in most cases (8/10). In some specimens, staining was weak but present in all tumor cells (Fig. 7E), whereas in other specimens, staining was confined to gobletlike cells positive for MUC2 (data not shown). A strong signal 

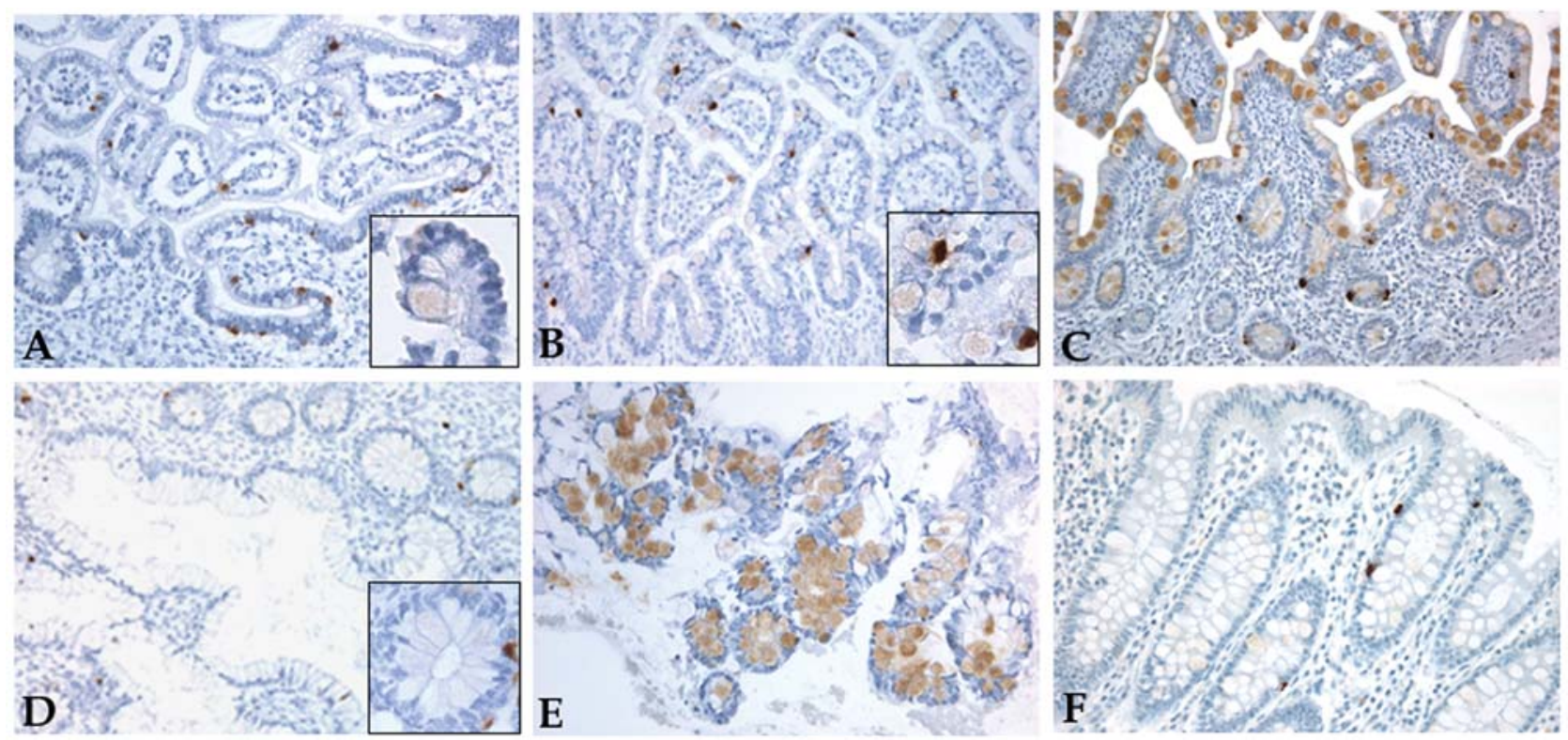

Figure 6. REG4 expression in fetal and adult intestine. (A) Fetal small intestine at 12 weeks. A strong staining is present in numerous enteroendocrine cells of primitive crypts and villi and a weak staining is present in rare goblet cells (insert). (B) Fetal small intestine at 16 weeks: a strong staining is present in enteroendocrine cells and a moderate staining is observed in most goblet cells (insert). (C) A similar expression pattern with more intense staining is observed in adult ileum. (D) Fetal colon at 16 weeks: a strong staining is present in some enteroendocrine cells and a weak staining is observed in a few goblet cells. (E) Fetal colon at 24 weeks: a strong staining is present in both enteroendocrine and goblet cells. (F) Adult colon: a strong staining is observed in enteroendocrine cells, and a weak staining is observed in rare goblet cells. Original magnification (A-F), x200.
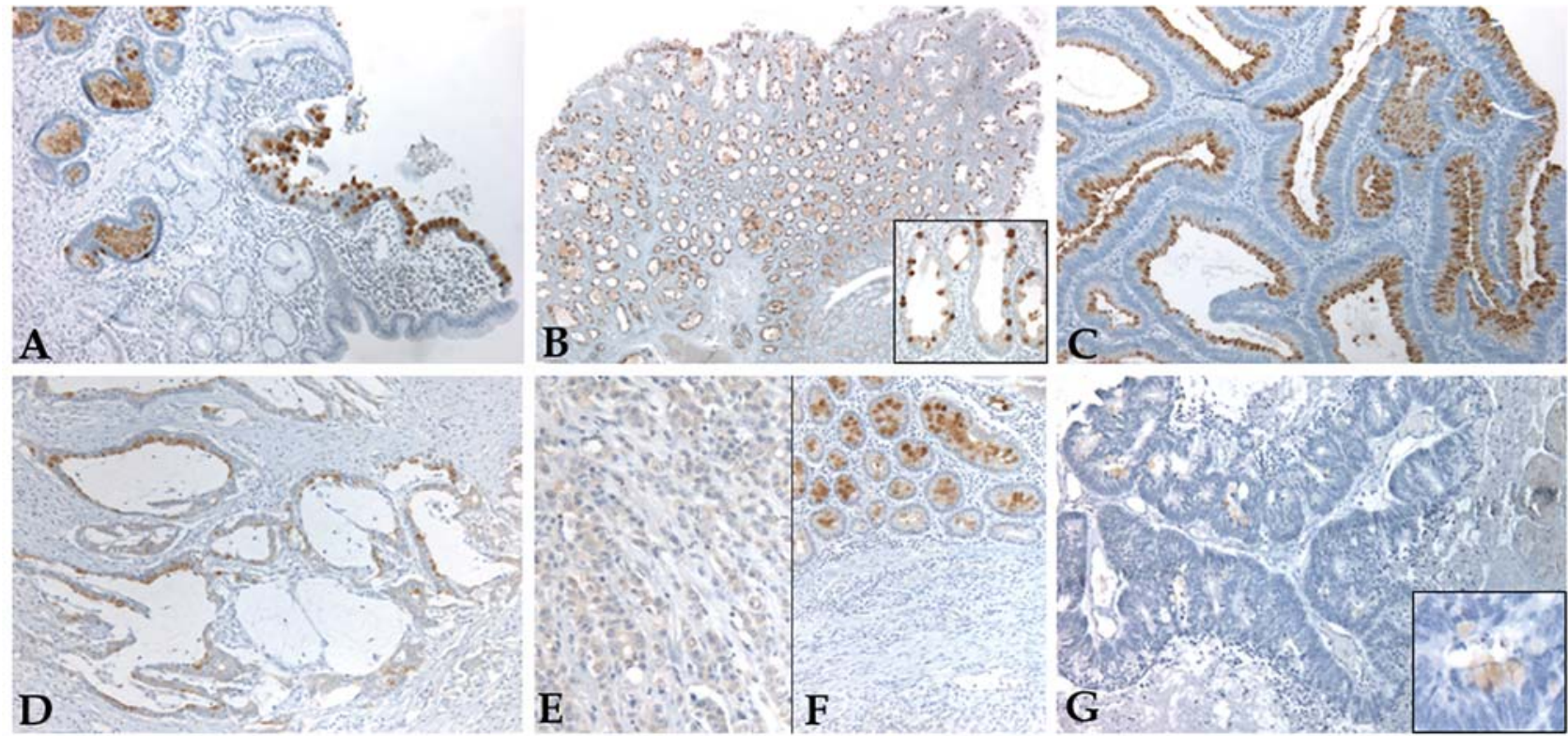

Figure 7. REG4 expression in pathological tissues. (A) Ileum from a patient with Crohn's disease: no REG4 staining is observed in the UACL, whereas a strong staining is present in the surrounding healthy mucosa, both in goblet and enteroendocrine cells. (B) Hyperplastic polyp: a strong REG4 staining is present in both enteroendocrine cells and goblet cells all along the epithelium of villi and crypts (insert). (C) Adenomatous polyps with high grade dysplasia: a strong REG4 staining is present in adenomatous cells, located essentially in residual mucous vesicles. (D-F) Colorectal carcinomas: D, mucinous adenocarcinoma: a strong staining is observed in tumor mucus-secreting epithelial cells; E and F, poorly differentiated carcinoma: a weak REG4 staining is present in all tumor cells (E), whereas a strong staining is observed in the adjacent normal mucosa, both in goblet and enteroendocrine cells (F). (G) Liver metastasis of a moderately differentiated colorectal adenocarcinoma: a moderate REG4 staining is observed in some mucus-secreting cells (insert). Original magnification: B, x25; A, C, D, F and G, x100; and E, x200.

was observed for Ki67 in all cases tested (data not shown). The pattern of REG4 expression was similar in the luminal and the invasive front of the tumors. Moreover, strong REG4 staining was observed in all specimens of carcinomas in the apparently normal mucosa adjacent to the tumor (i.e. transitional mucosa) (Fig. 7F). In liver metastases, REG4 was detected in some mucus-secreting cells in only 2 specimens (2/6) (Fig. 7G). 


\section{Discussion}

Previous studies on REG4 expression in various tissues from our laboratory and others have suggested a potential role of REG4 in colonic and gastric carcinogenesis $(6,7)$. However, little information exists on the biological function of the protein. REG4 may regulate cell growth and apoptosis, allowing cancer cells to proliferate and escape therapeutic agent- or radiation-induced death $(10,12)$. We previously described strong expression of the REG4 gene in colon cancer cell lines exhibiting a capacity for drug-resistance (6). As some of these cell lines also displayed invasive properties $(17,26)$, we further investigated the role of REG4 in this process. In this study, we showed that REG4, not only stimulates cell growth, but also promotes in vitro motility and invasiveness of colon cancer cells, two important processes in tumor progression. Our results on the tissue expression patterns of REG4, coupled with the present description of the biological functions of the protein, support a multifunctional role for REG4 in the gut, not only during carcinogenesis but also during physiological processes such as morphogenesis and wound healing.

REG4 is a growth factor for colon cancer cells, with an evident paracrine effect. As demonstrated using cell count assays, exogenous REG4 is able to stimulate the growth of cancer cells during a 24-h period following treatment. In a recent study, Bishnupuri and co-workers observed a similar increase in cell growth after $72 \mathrm{~h}$ post-treatment with REG4 (12). We also investigated, over a 72-h period, the effects of REG4 protein on cells. In our experimental conditions (i.e. daily addition of rREG4 according to the recurring REG4 secretion by tumor cells), the cell growth was continually activated, but the level of stimulation remained unchanged (Caco-2) or even tended to decrease (HT-29) after 48 and $72 \mathrm{~h}$ of treatment. Interestingly, the HT-29-derived clones, HT29-5M21 and HT29-5F7, which secrete large amounts of endogenous REG4, had a low proliferation rate $(\sim 28$ and $32 \mathrm{~h}$ versus $\sim 24$ h for HT-29, respectively) (data not shown). These observations suggest that regulatory mechanisms might restrict the stimulation of growth induced by REG4, particularly in the course of time. In addition, continuous overexpression of REG4 by the HT29/REG4-8 clone did not affect its growth. The same observation was previously reported in a gastric cancer cell line stably transfected with a vector expressing REG4 (10), but not in stably transfected cells derived from the colon cancer cell line DLD-1 (5). Therefore, it seems that REG4 might act in an autocrine or paracrine manner, depending on the target cell, to stimulate growth of colon cancer cells. In agreement with these observations, analysis of tissue expression patterns showed overexpression of REG4 in normal and pathological situations harboring increased proliferation, including the developing intestine, IBD, hyperplastic polyps, adenomas and CRC. In some cases, most of the cells expressing REG4 were not proliferating cells (i.e. enteroendocrine- and mucousdifferentiated cells) which also points towards a paracrine effect for the REG4 protein. Paradoxically, particular types of proliferating tumor cells, such as those located in adenomatous polyps, or in some poorly differentiated colorectal cancer tissues, are incontestably REG4-positive, suggesting that these tumor cells might be able to take advantage of an autocrine effect of REG4 secretion.

The most important aspect of our findings is that REG4 also acts as a motility and pro-invasive factor. This is the first study reporting the effects of REG4 on colon cancer cell migration and invasion, and little is known about the effects of REG proteins on these biological processes. A function linking cell migration and cell adhesion to the extracellular matrix was proposed for REG3A in hepatocyte cells (27) and in normal and transformed melanocyte cells (28). In this study, we showed that REG4 acts on tumor cell migration in both an autocrine and paracrine manner. Indeed, cells secreting REG4 or treated with exogenous REG4 showed a significantly greater migration potential compared to cells which did not express REG4, suggesting that REG4 may stimulate the migration potential of colon cancer cells but also of normal epithelial cells. This data is supported by the overexpression of REG4 in the fetal intestine (present study) and in injured intestinal mucosa in IBD [present study and (3-5)], specific situations in which epithelial cells display a high potential for migration. In the fetus, numerous REG4-expressing cells are present during the stages of villus formation in the small intestine (12-16 weeks) and gland formation in the colon (by 24 weeks) when compared to adults. Notably, in mice, REG1A was recently found to be involved in the generation and maintenance of the crypt-villus growth axis of the small intestinal mucosae by activating the growth of stem cells and migration of epithelial cells (29). Altogether, these data allow us to hypothesize a role for REG4 in intestinal morphogenesis, possibly by acting on cell proliferation and cell migration in a paracrine and autocrine manner. Moreover, REG4 may also be involved in epithelial restitution in IBD. As described in this study, REG4 was not expressed in the UACL which is thought to play a major role in epithelium restitution (30). REG4 was nevertheless overexpressed in the surrounding histologically normal mucosa and may thus facilitate epithelial restitution via paracrine stimulation of UACL.

In addition to cell migration, we also demonstrated that REG4 promotes in vitro invasion of colon cancer cells in both an autocrine and paracrine manner. At present, little is known about the potential effects of REG4 on cell invasion. A significant increase in the expression of the metalloproteinase matrylisin (MMP-7), an important molecule within the invasion front (31), was observed in colon cancer cell lines in response to REG4 treatment (12), suggesting indirectly that REG4 may be involved in the initial step of invasion. Although we found that most metastatic colonic cancers express REG4, no difference was observed in the expression patterns between the invasion front and the luminal front. However, REG4 secreted by neighboring cells (tumor cells and cells of the transitional mucosa) may act in a paracrine manner on tumor cells to promote local invasion. Furthermore, a high level of expression of REG4 protein in sera from patients with CRC has recently been related to the presence of liver metastases (11). In our study, only a few cases expressed REG4 in liver metastases. As we finalized our study, REG4 was reported to play a role in peritoneal metastasis in gastric carcinomas (32). The authors showed that REG4transfected human gastric cancer cells inoculated into the 
peritoneal cavities of nude mice produced peritoneal tumors in greater number and of larger size than with untransfected cells. However, these results should be interpreted with caution given the methodology used to analyze the metastatic potential of REG4-expressing cells: the site of tumor growth being the same as the site of cell inoculation. Further studies are required to investigate the potential role of REG4 in metastasis in both gastric and colorectal cancer. At present, REG4 can be considered as a protein overexpressed by tumor and epithelial cells of the transitional mucosa [present study and (11)] which may play an important role in colorectal carcinogenesis from the first steps of tumor development. Indeed, REG4 expression was shown to be deregulated early on in aberrant crypt foci $(33,34)$ and in adenomatous polyps regardless of the grade of dysplasia (present study). REG4 overexpression is maintained in most colorectal carcinomas [present study and $(6,7,11)]$. Recently, REG4 has been proposed as a marker for poor survival in patients with colorectal cancer (11), as previously reported for REG1A and REG3A (35).

Little is known regarding the signaling pathways that might be activated by REG4. To date, no receptor for REG4 has been identified. However, the biological effect of REG4 on cell proliferation could involve the EGF-receptor and subsequent Akt activation (12). Notably, regarding the intracellular signaling pathways known to be activated during the invasion process, we showed that several pathways, including PI3K/Akt, but also PKAs, PKCs and Rho-like GTPases, are involved in REG4 invasion signaling. Therefore, it seems that REG4 may stimulate both the proliferation and invasion of tumor cells through Akt pathway activation. Other members of the REG family can also trigger activation of the Akt pathway in various cell types (gastric cancer cells or neuronal cells) and, subsequently, lead to cell proliferation and/or survival $(1,36,37)$. Further studies are necessary to understand REG4 signaling and to analyze which pathways are involved in each of the biological processes stimulated by REG4, including cell proliferation, migration and invasion but also cell survival and cell resistance to chemotherapy. Recently, REG4 has been shown to be an anti-apoptotic factor in colon and gastric cancer cells $(10,12)$. REG4 has also been proposed as a promising marker to predict resistance to 5fluorouracil-based chemotherapy in patients with gastric cancer (10). Notably, we first identified REG4 in the HT-29 models, HT29-5M21 and HT29-5F7 clones, selected by drugtreatment of HT-29 cells. These clones are characterized by their drug-resistant and invasive phenotype which contrasts with that of HT-29 parental cells which do not express REG4 [our present and previous studies $(13,14,18)]$. Altogether, these data suggest that REG4 may participate in the drugresistance and invasiveness of colorectal tumor cells, leading to the appearance of tumor cells displaying a more aggressive phenotype.

In summary, REG4 is a multifunctional secreted protein which acts on intestinal cell proliferation, migration and invasion as supported by our results in in vitro models. Its overexpression in various normal and pathological situations such as the developing intestine, and inflammatory, preneoplastic and neoplastic intestine suggests that REG4 may play an important role in the development and progression of colorectal cancer as well as in intestinal morphogenesis and epithelium restitution.

\section{Acknowledgements}

We thank Amandine Ketele for the excellent technical assistance and Dr Olivier De Wever for helping us to set up the collagen invasion assay. This research was supported by Inserm-Lille 2 University-CHRU Lille, Cancéropôle NordOuest, Ligue Contre le Cancer and Région Nord-Pas de Calais. L. Rafa received a grant from Région Nord-Pas de Calais-CHRU de Lille.

\section{References}

1. Iovanna JL and Dagorn JC: The multifunctional family of secreted proteins containing a C-type lectin-like domain linked to a short N-terminal peptide. Biochim Biophys Acta 1723: 8-18, 2005.

2. Okamoto H: The Reg gene family and Reg proteins: with special attention to the regeneration of pancreatic beta-cells. J Hepatobiliary Pancreat Surg 6: 254-262, 1999.

3. Hartupee JC, Zhang H, Bonaldo MF, Soares MB and Dieckgraefe BK: Isolation and characterization of a cDNA encoding a novel member of the human regenerating protein family: Reg IV. Biochim Biophys Acta 1518: 287-293, 2001.

4. Kamarainen M, Heiskala K, Knuutila S, Heiskala M, Winqvist O and Andersson LC: RELP, a novel human REG-like protein with up-regulated expression in inflammatory and metaplastic gastrointestinal mucosa. Am J Pathol 163: 11-20, 2003.

5. Nanakin A, Fukui H, Fujii S, Sekikawa A, Kanda N, Hisatsune H, Seno H, Konda Y, Fujimori T and Chiba T: Expression of the REG IV gene in ulcerative colitis. Lab Invest 87: 304-314, 2007.

6. Violette S, Festor E, Pandrea-Vasile I, Mitchell V, Adida C, Dussaulx E, Lacorte JM, Chambaz J, Lacasa M and Lesuffleur T: Reg IV, a new member of the regenerating gene family, is overexpressed in colorectal carcinomas. Int J Cancer 103: 185-193, 2003.

7. Oue N, Mitani Y, Aung PP, Sakakura C, Takeshima Y, Kaneko M, Noguchi T, Nakayama H and Yasui W: Expression and localization of Reg IV in human neoplastic and non-neoplastic tissues: Reg IV expression is associated with intestinal and neuroendocrine differentiation in gastric adenocarcinoma. J Pathol 207: 185-198, 2005.

8. Gu Z, Rubin MA, Yang Y, Deprimo SE, Zhao H, Horvath S, Brooks JD, Loda M and Reiter RE: Reg IV: a promising marker of hormone refractory metastatic prostate cancer. Clin Cancer Res 11: 2237-2243, 2005.

9. Bishnupuri KS, Luo Q, Korzenik JR, Henderson JO, Houchen CW, Anant S and Dieckgraefe BK: Dysregulation of Reg gene expression occurs early in gastrointestinal tumorigenesis and regulates anti-apoptotic genes. Cancer Biol Ther 5: 1714-1720, 2006.

10. Mitani Y, Oue N, Matsumura S, Yoshida K, Noguchi T, Ito M, Tanaka S, Kuniyasu H, Kamata N and Yasui W: Reg IV is a serum biomarker for gastric cancer patients and predicts response to 5-fluorouracil-based chemotherapy. Oncogene 26: 4383-4393, 2007.

11. Oue N, Kuniyasu H, Noguchi T, Sentani K, Ito M, Tanaka S, Setoyama T, Sakakura C, Natsugoe S and Yasui W: Serum concentration of Reg IV in patients with colorectal cancer: overexpression and high serum levels of Reg IV are associated with liver metastasis. Oncology 72: 371-380, 2007.

12. Bishnupuri KS, Luo Q, Murmu N, Houchen CW, Anant S and Dieckgraefe BK: Reg IV activates the epidermal growth factor receptor/Akt/AP-1 signaling pathway in colon adenocarcinomas. Gastroenterology 130: 137-149, 2006.

13. Leteurtre E, Gouyer V, Rousseau K, Moreau O, Barbat A, Swallow D, Huet G and Lesuffleur T: Differential mucin expression in colon carcinoma HT-29 clones with variable resistance to 5-fluorouracil and methotrexate. Biol Cell 96: 145-151, 2004.

14. Lesuffleur T, Violette S, Vasile-Pandrea I, Dussaulx E, Barbat A, Muleris $\mathrm{M}$ and Zweibaum A: Resistance to high concentrations of methotrexate and 5-fluorouracil of differentiated HT-29 colon-cancer cells is restricted to cells of enterocytic phenotype. Int J Cancer 76: 383-392, 1998. 
27. Christa L, Carnot F, Simon MT, Levavasseur F, Stinnakre MG, Lasserre C, Thepot D, Clement B, Devinoy E and Brechot C: HIP/PAP is an adhesive protein expressed in hepatocarcinoma, normal Paneth, and pancreatic cells. Am J Physiol 271: G993-G1002, 1996.

15. Lesuffleur T, Barbat A, Dussaulx E and Zweibaum A: Growth adaptation to methotrexate of HT-29 human colon carcinoma cells is associated with their ability to differentiate into columnar absorptive and mucus-secreting cells. Cancer Res 50: 6334-6343, 1990.

16. Lesuffleur T, Kornowski A, Luccioni C, Muleris M, Barbat A, Beaumatin J, Dussaulx E, Dutrillaux B and Zweibaum A: Adaptation to 5-fluorouracil of the heterogeneous human colon tumor cell line HT-29 results in the selection of cells committed to differentiation. Int J Cancer 49: 721-730, 1991.

17. Truant S, Bruyneel E, Gouyer V, De Wever O, Pruvot FR, Mareel M and Huet G: Requirement of both mucins and proteoglycans in cell-cell dissociation and invasiveness of colon carcinoma HT-29 cells. Int J Cancer 104: 683-694, 2003.

18. Gouyer V, Fontaine D, Dumont P, et al: Autocrine induction of invasion and metastasis by tumor-associated trypsin inhibitor in human colon cancer cells. Oncogene 27: 4024-4033, 2008.

19. Zweibaum A, Pinto M, Chevalier G, Dussaulx E, Triadou N, Lacroix B, Haffen K, Brun JL and Rousset M: Enterocytic differentiation of a subpopulation of the human colon tumor cell line HT-29 selected for growth in sugar-free medium and its inhibition by glucose. J Cell Physiol 122: 21-29, 1985.

20. Chantret I, Rodolosse A, Barbat A, Dussaulx E, Brot-Laroche E, Zweibaum A and Rousset M: Differential expression of sucraseisomaltase in clones isolated from early and late passages of the cell line Caco-2: evidence for glucose-dependent negative regulation. J Cell Sci 107: 213-225, 1994.

21. Dignass A, Lynch-Devaney K, Kindon H, Thim L and Podolsky DK: Trefoil peptides promote epithelial migration through a transforming growth factor beta-independent pathway. J Clin Invest 94: 376-383, 1994.

22. Toback FG, Walsh-Reitz MM, Musch MW, Chang EB Del Valle J, Ren H, Huang E and Martin TE: Peptide fragments of AMP-18, a novel secreted gastric antrum mucosal protein, are mitogenic and motogenic. Am J Physiol Gastrointest Liver Physiol 285: G344-G353, 2003.

23. Bracke M, Boterberg T and Mareel M: Collagen invasion assay, chick heart invasion assay. In: Metastasis Methods and Protocols. Humana Press, Totowa, 2000.

24. Buisine MP, Desreumaux P, Leteurtre E, Copin MC, Colombel JF, Porchet $\mathrm{N}$ and Aubert JP: Mucin gene expression in intestinal epithelial cells in Crohn's disease. Gut 49: 544-551, 2001.

25. Hovenberg HW, Davies JR, Herrmann A, Linden CJ and Carlstedt I: MUC5AC, but not MUC2, is a prominent mucin in respiratory secretions. Glycoconj J 13: 839-847, 1996.

26. Suzuki A, Lu J, Kusakai G, Kishimoto A, Ogura T and Esumi H: ARK5 is a tumor invasion-associated factor downstream of Akt signaling. Mol Cell Biol 24: 3526-3535, 2004.

8. Valery C, Vasseur S, Sabatier F, Iovanna JL, Dagorn JC, Grob JJ and Verrando P: Pancreatitis associated protein I (PAP-I) alters adhesion and motility of human melanocytes and melanoma cells. J Invest Dermatol 116: 426-433, 2001.

29. Ose T, Kadowaki Y, Fukuhara H, Kazumori H, Ishihara S, Udagawa J, Otani H, Takasawa S, Okamoto H and Kinoshita Y: Reg I-knockout mice reveal its role in regulation of cell growth that is required in generation and maintenance of the villous structure of small intestine. Oncogene 26: 349-359, 2007.

30. Wright NA, Pike C and Elia G: Induction of a novel epidermal growth factor-secreting cell lineage by mucosal ulceration in human gastrointestinal stem cells. Nature 343: 82-85, 1990.

31. Masaki T, Matsuoka H, Sugiyama M, Abe N, Goto A, Sakamoto A and Atomi Y: Matrilysin (MMP-7) as a significant determinant of malignant potential of early invasive colorectal carcinomas. Br J Cancer 84: 1317-1321, 2001.

32. Kuniyasu H, Oue N, Sasahira T, Yi L, Moriwaka Y, Shimomoto T, Fujii K, Ohmori H and Yasui W: Reg IV enhances peritoneal metastasis in gastric carcinomas. Cell Prolif 42: 110-121, 2009.

33. Glebov OK, Rodriguez LM, Soballe P, DeNobile J, Cliatt J, Nakahara K and Kirsch IR: Gene expression patterns distinguish colonoscopically isolated human aberrant crypt foci from normal colonic mucosa. Cancer Epidemiol Biomarkers Prev 15: 2253-2262, 2006

34. Schroder N, Sekhar A, Geffers I, Muller J, Dittrich-Breiholz O, Kracht M, Wedemeyer J and Gossler A: Identification of mouse genes with highly specific expression patterns in differentiated intestinal epithelium. Gastroenterology 130: 902-907, 2006.

35. Macadam RC, Sarela AI, Farmery SM, Robinson PA, Markham AF and Guillou PJ: Death from early colorectal cancer is predicted by the presence of transcripts of the REG gene family. Br J Cancer 83: 188-195, 2000.

36. Nishimune H, Vasseur S, Wiese S, Birling MC, Holtmann B, Sendtner M, Iovanna JL and Henderson CE: Reg-2 is a motoneuron neurotrophic factor and a signalling intermediate in the CNTF survival pathway. Nat Cell Biol 2: 906-914, 2000.

37. Sekikawa A, Fukui H, Fujii S, Takeda J, Nanakin A, Hisatsune H, Seno H, Takasawa S, Okamoto H, Fujimori T and Chiba T: REG Ialpha protein may function as a trophic and/or antiapoptotic factor in the development of gastric cancer. Gastroenterology 128: 642-653, 2005. 